\title{
CONSIDERATIONS REGARDING THE COMPLEX NATURE OF JUDICIAL HEARINGS PREPARATION
}

\author{
G. I. Olteanu
}

\section{Gabriel-Ion Olteanu}

Faculty of Law, the Forensic Department, Police Academy "Alexandru Ioan Cuza", Bucharest, Romania

*Correspondence: Gabriel Ion Olteanu, Police Academy "Alexandru Ioan Cuza", 1A Aleea Privihetorilor St., Sector 1, Bucharest, Romania.

E-mail: gabrielolteanu10@gmail.com

\begin{abstract}
The author takes over and develops a classic theme of the criminal discourse: preparation for interrogation. By presenting the considerations related to less analysed aspects of the doctrine and ignored by the Romanian investigators, the author brings to attention a theme for meditation both necessary and profound-from adequate preparation of the judicial hearing to the heard person's scientific evolution and personal needs.
\end{abstract}

Keywords: Judicial hearing, judicial interview and interrogation, investigator, suspect, hearing effectiveness

\section{Introduction}

Practitioners say that two minutes of preparation can save several hours of investigation. Although judicial hearings can take place outside a formal framework, proper preparation is essential for the success of any hearing. In the street, at a person's domicile, in the offices of a multinational company or in the hearing room, the investigator's performance must be attentively prepared. He/she must not forget that he/she has specific objectives of the investigation which must be carried on, that the investigated person has his/her own interests and behavior and that nothing was ever easy to do within a criminal investigation. The preparation of judicial hearings is not only complex but also compulsory. If the obligation means to observe the previsions of legal norms and criminal tactics assimilated by the professional environment, then when we speak of complexity, we must have in mind the investigator's active thinking. The investigator has to adjust himself/herself to each person and case particularities. The simple application of patterns cannot bring the necessary success in each investigator's undertaking.

The preparation of hearing within judicial investigations means, in a classic approach, to determine the issues which have to be settled within the hearing, the order in which the evidence presented has to be used, the establishment of tactic procedures of hearing, according to the data obtained regarding the accused or defendant's psychology and personality as well as the circumstances in which the crime was committed. ${ }^{1}$ I consider that here it is necessary to notice certain evolutions and, as a consequence, pay the necessary attention to certain elements further described.

The hearing objectives - a person's hearing results in obtaining an important amount of information useful for the ongoing investigation development where it is highly important that the investigator adequately evaluates the nature and importance of the information obtained.

\footnotetext{
${ }^{1}$ C. Aionițoaie, T. Butoi, Ascultarea învinuitului sau inculpatului, in Tratat de tactică criminalistică, "Carpați”" Printing House, Craiova, 1992, p. 91.
} 
The investigators usually find it necessary to approach the investigation general framework, ask questions which allow the investigated person to offer a large amount of information. It is considered that important unsolicited information is actively revealed for the investigator. Thus, the "information sources" can be protected; information which cannot be otherwise provided is thus verified.

Each important information has to be attentively analysed - the context it was communicated in, its relevance to the person who offered it, normal personal relations and purposes which are pursued, the non-verbal manifestations in this case, etc.

Every time, after the stage of the easy approach, it is necessary to use rigour as the rule says that each person who testifies within a criminal investigation uses the testimony as an "alibi", as recitals in order to support his/her own interests. Everything has to be as complete as possible in order to precisely establish what is true and false. Even more, one must not forget the necessary correlations between the heard person's declarations and his/her behaviour at different times during the hearing.

The evidence available in the file - in order to know the evidence which can be used within the hearing, the investigator should have in view the possible answers which can be given by the suspect when confronted with each piece of evidence. Obviously, the investigator cannot determine the suspect not to offer erroneous explanations regarding the aspects and circumstances for which there is incriminating evidence. What can be done is that the investigator conducts the suspect's answers - refer to circumstances or aspects which later on can be blocked with other highly convincing evidence. Thus, lies can be controlled by overvaluation in circumstances of inability to offer evidence to support over dimensional lies and/or by referring to "regular lies" which are so usual that nobody believes in.

General information - behind this notion there must lay the investigator's so called general knowledge regarding the case under investigation. Basically, it refers to any information about the people involved, the crime scene, the formal and/or factual rules which govern a certain economic or administrative activity related to the illicit did. Any information could be useful - it is easier to discover lies fabricated by the suspects hoping that the investigator does not know certain information; information which cannot be known by "anyone". Even more, in the case of managed intakes such as public acquisitions or accountancy or the way a certain internal labor methodology "works", the suspects base their lies by relying on "convenient" lies.

It is also possible that the listener has a "hidden agenda", something which can influence their behavior.

The investigator must not forget that the heard persons' audition order within a case is very important. It is hard to give advice in this field - Who should be the first? The oldest, the youngest, women, the main suspect, the victim, in case there are several suspects, who should be the first? etc Inspiration can help save time and energy.

If the alleged criminal or the main suspect, as we can never be sure enough, finds out that another participant in illicit activities such as a co-author, accomplice, instigator, someone who has organized and/or financed an illicit activity - will have an extra reason of stress and a concern which he/she will try to hide in order not to be discovered by the investigators.

The order in which the people undergoing an investigation are heard in routine cases is not very important as it is done according to the investigator's wish. In special cases, where undercover investigators were used and the information was obtained from certain informers, it is recommended to establish the hearing order at administrative level after serious previous risk analysis has been done.

The way in which each hearing is done, the "choreography" according to which the heard people are moved from one room to another, "the surprise meetings" on the hallway or the "doorway", the investigators' replacement, the pauses, the meals, the visit to the room with the corpora delicti, etc can highly influence the results of the investigation. 
Within the doctrine ${ }^{2}$, the way in which the suspect reacted along previous hearings how did the suspect react when meeting the investigators? is highly debated. Was he docile, did he react violently, did he try to use illness as a means of avoiding the hearing in the hearing room, did he pretend to faint, etc?

Experienced investigators know the fact that most people adopt typical behaviour in typical situations that they go through. Under these circumstances, the suspect who was verbally aggressive within the research 3-4 years ago is expected to behave in the same manner each time he/she is heard during an investigation.

Normally, this type of information is extremely useful but obtaining it is not easy as it is not always easy to find people who know enough information based on which the dominant trait of behavior can be determined in a special situation such as the development of a judicial hearing according to which we can find out the normal behavior of the person undergoing the investigation.

Investigator appointment - in practice, it is considered as a good solution for the development of the hearing underdone by the investigator who manages the case file. Still, often, he is not the most suitable person to pursue certain hearing. Even though he could have the best representation of the investigation stage, has the strategic option regarding the investigation evolution, or has heard several people or all people involved in the investigation, the investigator may not obtain the suspect's trust as there is suspicion (often real) that the investigator is already convinced that the suspect is guilty. There is the possibility that the investigator had certain contact with the suspect - the occasion which has led to a conflict such as a communication barrier - or an arrest and other hard feelings, etc. Even more, in certain cases it is possible that the suspect had been the investigator's superior. ${ }^{3}$ Also, it is possible to lead to cultural or gender problems - a woman investigator will face more resistance if she hears a male suspect with rigid, traditional opinions regarding cultural and gender differences - which have to be taken into account when the investigator decides to conduct the hearing. In many cases, it refers to a so-called politics of the judicial organisms which approaches the case under the pressure of the public opinion, higher administrative institutions, mass-media, natural desire to close the case, to provide examples for the society. ${ }^{4}$

The case file and the evidence - during a suspect's hearing, each detail can become very important.

In fact, the case file is a file...which contains, beyond the specific criminal terminology, pages with the investigation data, regardless of their names - minutes, declarations, reports, etc. It is tangible, represents the present stage of the investigation and could be used by the investigator in order to amplify the pressure on the suspect. The investigator can admire or touch it and say "Look what we've got here", "Let's see what it's written here", "Yes, it's an obvious... waste of time". In fact, he can be either convincing or not or at least give the impression that "he understood how things work", that he has the results of certain activities which, in fact, have not taken place - declarations of people who had not been heard, minutes of undone searches, reports of expertise which has not been done, etc.

At least, as a principle, it is not advisable to use these types of elements - video cassettes, objects used during the illicit activities, objects bearing traces which confirm the person's presence at the crime scene - which could complicate the "image" presented to the suspect. The motive is simple - the suspect may entirely refuse to make any declaration: "if

\footnotetext{
2 J. K. Barefoot, Employee Theft Investigations, Butterworth Publishers, Stoneham, Mass., 1980, p. 57.

Author's note - it is possible that the investigator, before joining the judicial police, or a close relative or friend had had a subordination relation with the suspect and this affects the good development of the hearing

${ }^{4}$ D. Zulawski, D. Wicklander, Practical Aspects of Interview and Interrogation, CRC Press, LLC, 2002, p. 59. It is highlighted the fact that in the private environment, everything is decided according to the company's politics and interests; in the public sector, the situation is slightly different as the situation is never abandoned before the legal procedures are finalized.
} 
there is so much evidence, why do you need my declaration?" Even more, there is the possibility that the suspect asks to see the evidence which proves his involvement.

Although it may resemble a humbug, it is advisable that the investigator carefully manages only the file and allows the suspect reach his own conclusions regarding what he may obtain.

In most cases, the investigator, while preparing to hear a suspect, pursues it with little evidence against him. Sometimes, it involves only indirect evidence or the results of a reasoning based on simple logics.

Under these circumstances, the file can be used as a bench-mark, as a support element for the investigator; he can only refer to the file existence with a lateral head movement, with an explicit or resolute inclined head movement. The investigator can get back and approach the file in a threatening way as "this doesn't work anymore". Anyway, the file will contain the forms necessary for declarations, minutes, etc. A suspect's hearing should not be interrupted, the investigator being prepared for anything. It is important for his mind to be "set" in order to obtain the suspect's confession.

Regarding the guilt evidence, I believe that it has to be prepared seen after the suspect's clear position in relation to each evidence in part. Of course, to the extent to which a scenario is drawn and a positive reaction is expected, for the investigation, the investigators can leave an object to the suspect's sight which relates him to direct involvement in the illicit activity. Every time an object, a writ, or any other object which can be considered evidence is present in the hearing room, the investigator must take the necessary measures for the evidence protection - the suspect may destroy, swallow, throw the evidence out of the window, etc.

Time interval and the place of hearing - usually, investigators have the possibility to establish and rigorously prepare the time interval and the room for the hearing. If the hearing is done with the occasion of new activities on the field - such as research at the crime scene, search, or in flagrante delicti situation - the investigator has few options and, as a result, there cannot be real preparation.

In spite of all these, it is advisable that the investigator undergoes the hearing in an "intimate area" which can ensure confidentiality and facilitates communication. Thus, there is the risk that the suspect's concentration diminishes. Even more, people with hidden interests or passersby can interfere so that both the heard person and the investigator's security are at risk. Sometimes it is enough that the investigator changes the place of "discussion" by a few meters, other times, and the place can be the police car (the better equipped with listening and image devices, the better). It is very important that the heard person had undergone body search before hearing as it is important not to under consider the risk of carrying guns with the purpose of hostage taking.

The hearing intimacy, the confidentiality of the information revealed is highly important in order to obtain the information necessary for the investigation. Investigators must have in view the fact that the declarations can have extremely important consequences for the heard person and his/her relatives. One cannot explain something illegal, shameful, or wrong in any circumstances. One can hardly confess in front of a trustworthy person; under no circumstances in front of several people or the mass-media. Usually, secrets are told in moments of intimacy.

The purpose of the hearings underdone on the field, as is the crime scene case, means to obtain information regarding the nature of the activities, the identity of the people involved, the motifs, the circumstances under which the activity took place and so on. Although there are resemblances between a formal hearing and a crime scene hearing, there are also differences, of which the most important are the following:

- Certain spontaneity of the declarations obtained based on lack of preparation due to confusion, strong emotions, the time lapsed, impossibility to obtain a satisfying level of 
concentration to synthesize the interests and aspects of different circumstances which may be important;

- Incertitude regarding the suspects' guilt;

- Incertitude regarding the deed consequences;

- The need to obtain as many and as detailed information based on which the research is extended.

The heard person and any other suspect can be arrested based on the hearing results underdone at the crime scene. The more the hearings were underdone by respecting confidentiality and the heard persons were convincing regarding their testimonies, the more confident the investigator becomes and the better the investigation is led.

Usually, the investigators undergo hearings in the offices or houses where the witnesses or the victims carry their daily activities. There are many disadvantages where the most important are interruptions due to telephone calls, arrival and/or intervention of a third person, children, etc. These types of interruptions can draw attention; can offer the necessary time to the heard person to make up a story full of lies - more or less credible - can make certain drainage in a not so well systematized memory which tries to do something with uncertain information.

The hearing outside the judicial office must be accepted as part of the hearing - it has to be done for several reasons such as: the main suspect has not been identified yet, it is necessary to obtain the suspects' alibis, the fact that one person had been called at the police station should remain unknown, etc - and, under these circumstances, hearings have to be properly prepared. Thus, it is preferable that the investigator waits, if necessary, for the time interval which allows the hearing to take place in "silence", in a confident area, where the interviewed people feel comfortable and totally attentive and nimble regarding the judicial procedure.

The hearing place must ensure confidentiality and intimacy and this is possible in a private framework. If there are no interruptions, if there are no distractive events, it is possible that the heard person can focus on the hearing, on what he/she has to say, the way he/she testifies. It is advisable that the investigator prepares the heard person so that he/she can focus on the investigation, the effort to identify the criminal, etc thus avoiding as much as possible the less desirable consequences of altering the declarations during the investigation.

The hearing room, beyond the fact that it has to be available during the entire hearing, must be decorated so that it does not influence the investigated person in a negative manner, does not inspire cold atmosphere which might limit communication; the investigated person should not want to end the hearing too early. The room can generate fear, it can amplify the fear feeling in relation to what might happen worse in the investigation development. In this type of atmosphere, the investigated person is tempted to deny everything, avoid offer the investigator any type of information.

The choice of a common-looking office, with specific furniture, which is familiar to several investigated people, is a good solution. Everything has to look familiar. Although one might say that this type of room does not offer the investigator the facilities of a hearing room, still, the warmth and comfort can lead to less resistance, less preoccupation for defence specific to most people who undergo investigation with criminal investigation. Even more, communication is facilitated and even encouraged. In an office, jokes can be told - the official nature of the hearing has to become more familiar - the investigator can move, notice something on the wall or out of the window. It is important that the atmosphere specific to a confrontation, expected by the person who has to be heard, is not confirmed, is not present.

Even more, the investigator could use a third person to be present as witness during the hearing. On condition that this person is trustworthy, there are a few advantages which should not be neglected, such as: 
- There is a second person who can confirm the fact that during the investigation there have not been any threats, illegal promises, no constraint measures were used in order to offence the heard person's honor and dignity, etc.;

- There is a second set of eyes and ears which observe what is being said as well as the investigator and heard person's behavior;

- The assistant witness (who can also be another investigator, the second investigator) hears and observes everything that had taken place during the hearing although the two investigators' perception cannot be identical, evaluations regarding the investigator's responsibility and professionalism can be done.

- In case the main investigator does not know that the assistant witness is also an investigator, there is the possibility that the second investigator presents later on his/her own result of the hearing;

- In case of any incident or cause which makes ineffective the first investigator's endeavor, based on a sign of maybe a scenario, the second investigator will be able to take over the hearing.

Regarding the positions, it is advisable that the heard person stays with his/her back to the door ${ }^{5}$. The assistant witness or the second investigator should be positioned slightly in the lateral of the heard person, out of the reach of peripheral view of the heard person so that he/she would not be distracted during the hearing. The heard person while seated with the back at the door will not feel the need to leave and will not feel as if he/she is kept in the room due to the fact that the exit is blocked by the investigator, as he/she positions his/her chair on the door trajectory. One should not neglect the fact that an assistant witness/ the second investigator is a woman could be an advantage in case of a male duel.

Referring back to the hearing room, at the natural positive impact of the comfort on the heard person, I mention that it is good not to have an object inflation, not to create a crowded image as this will willingly or unwillingly diminish the heard person's attention as he/she focuses on an object or several objects displayed in the room. The fewer reasons, the fewer objects which draw attention, the easier for the investigator to interpret what determined the investigated person's behavior - each behavioral act analyzed in association with what the heard person writes or says.

If in an office it is easy for the investigator to analyze and understand the heard person's behavior, things change a lot when hearing is underdone in a street with an aggressive barking dog, a car with lights on or a speeding car, another person who has to ask or say something, etc. Under these circumstances, there is a variable in the heard person's behavior which makes it more difficult for the investigator to interpret his/her behavior. The same may happen if the investigated person is directly or indirectly allowed to smoke by offering him/her an ashtray - everything becomes more complicated. What we see as behavior manifestation is the result of the possibility to smoke, is a specific manifestation when perceiving tobacco flavor, the joy of nicotine recognition, etc. For example, if the suspect, as an answer to the investigator's questions directs his/her hand to his/her pockets, takes out the pack of cigarettes, takes one cigarette and tries to light it although he/she hasn't finished the light one - will be interpreted by the investigator as a manoeuvre to gain time or will be considered as a reflexive gesture manifested each time the person has something important to do.

The same happens when the heard person is offered something to drink. When the suspect leisurely takes the glass and sips, he/she wants to delay the answer or it is a simple coincidence or a result of emotional tension specific to judicial hearing. Leaving pencils, paper clips or other objects on the desk at the heard person's disposal can create similar interpretation problems - if the investigated person starts playing with a paper clip which

\footnotetext{
5 D. Zulawski, D. Wicklander, Practical Aspects of Interview and Interrogation, CRC Press, LLC, 2002, p. 63 .
} 
he/she bends, this means that the suspect either avoids to look at the investigator, lies, or likes to play with the paper clip. It is obvious that in most cases the investigated persons will try to get time in order to formulate the best answer according to his/her interests.

A further source of attention distraction is the investigator's power and valorization of signs. I recall that some time ago I went on a documentation trip to Italy and while invited in a police officer's office, I was impressed by a big framed picture extracted from a paper which showed the policeman as a young and victorious man with the gun in his hand beside a Mafia boss. The text following the picture was eloquent: "The mafia godfather has found his policeman godfather, congratulations to the policeman, congratulations to the policeman... for catching the dangerous mobster!" Along the entire visit, I watched this picture and the policeman's victorious smile and his gun at the mobster's head created a strange sensation. Other objects can also be used, such as: the plaque which reveals the merits, badges placed on the uniform, the pistol, the handcuffs insidiously moved from time to time, can build an emotional state of mine for the suspect -it is a special situation with serious consequences.

The heard person's attention can be influenced by several factors, some more important than others.

What can the investigator do? Probably the best thing would be to put himself in the heard person's shoes, visualize the hearing room and notice the sources of attention grabbing which could negatively influence the hearing development. He would probably take care of the draperies, the land line, and any other element in the superior part of the room.

If the hearing cannot take place in an office and a conference room, a warehouse are chosen instead, it is necessary to upgrade this space - minimum dust cleaned and the furniture arranged in a manner which facilitates communication.

Neither in the hearing are room, upgraded in the judicial headquarters, things simple. Usually, here we find a cold atmosphere, with closed air, and phonic isolation which allows no noise from the outside, the door's closing system, it is possible that the door and the windows - if they exist - have bars - nothing suggests comfort and openness to free communication so that neither an experienced investigator feels at ease. Although these hearing rooms have a clear role - for example, when arrested people are heard or further security measures are needed - it is advisable to use this type of rooms when investigators wish to put further pressure on the heard person after previous preparation. duel.

The investigator's preparation - It is often said that judicial hearing is a type of

What happens in fact?

The heard person becomes nervous, develops frustrations as he/she considers that he/she faces a rival who has to be defeated - the man who wants to find out more than he wants to tell and has to be defeated, should be put in his place and made understand that "if I want to tell something, I will tell, and if I don't want, nobody and nothing will convince me to do it". The investigator himself can become as nervous and frustrated as the heard person as he becomes nervous due to the situation and bothered by the fact that he does not have enough means to determine the person to change attitude. Thus, the investigator can change his attitude, become sarcastic, use indecent or malicious language, etc.

It would be probably best for the investigator to understand both the need and the negotiator. He must accept the idea that it is normal and it is the heard person's "job" to omit, forget, hide, find out, and try to trick the investigator in any way. Understanding the two main actors' roles - the investigator and the heard person - can lead to accepting the fact that conflict is not productive. As negotiator, the investigator can better manage the hostile feelings, frustrations, the way the criminal investigation should go, what might happen with one or other people involved in the illicit activity, how and if it is possible to recover the prejudice, etc. 
Without developing mediation theories, I believe it is necessary to have a "win win" situation. This will allow the investigator understand the heard person's situation and will also allow the heard person to understand that the investigator has something important to do and, in his position, he cannot afford to lose. The investigator cannot defend the heard person but can "negotiate" so that he finds out the truth and the truth - the most credible variant of the way the searched illicit activity took place -can support best the interest of the people involved.

As a negotiator, the investigator can think he can act as a theatre director: he can choose the setting, establish the choreography, the way each dialogue begins, can think of the way he will be able to use to hearing room, can establish the outfits - his; can also influence the heard person's outfit. For example, a lot of investigators consider that the outfit with a suit and tie is absolutely professional and fits all situations, which can be true in most cases. Still, there are cases where this type of outfit can generate limitations and distance as they lead to frustration relating to the investigator's wellbeing by comparison to more precarious financial situation of the investigated persons. The rule should mean that the investigator changes his outfit according to the heard person and take into account the heard person's needs ${ }^{7}$.

By anticipating the heard person's possible attitudes, the way he/she prepares and approached the hearing, the investigator should also prepare. He should chose his outfit, smile, own way of approach. This should mean the investigator adjusts his/her own approach and behavior - for predictable moments of the hearing, etc. With the risk of repeating myself, the investigator's behavior should be adequate to everything which could mean fury, suspicion, reserved attitude or despise. It would be better for the investigator to learn from a seller's behavior when faced with a possible client ${ }^{8}$. In sales, an agent must identify the client's needs - emotional, financial, self image, etc. - present the benefits of his product and highlight the way he answers to the client's needs. In principle, if the product's benefits can compensate the client's objections, and if the product satisfies the client's needs, he will buy it. In a similar way, within a hearing, the benefits seen as a result of communication with the investigator, information provision, will have to pass his objections. Otherwise, the heard person will not speak.

Bibliography:

C. Aionițoaie, T. Butoi, Ascultarea învinuitului sau inculpatului in Tratat de tactică criminalistică, "Carpați” Printing House, Craiova, 1992;

J. K. Barefoot, Employee Theft Investigations, Butterworth Publishers, Stoneham, Mass., 1980;

N. J. Gordon, W. L. Fleisher, Effective interviewing and interrogation techniques, Elsevier Inc., 2006;

D. Zulawski, D. Wicklander, Practical Aspects of Interview and Interrogation, CRC Press, Boca Raton LLC, 2002.

\footnotetext{
6 Author's note - in negotiation practice there are known four types of negotiation: win - win; loss - win; win - loss; loss - loss; all these types have advantages and disadvantages and can be used effectively by taking account of the negotiation object

7 Author's note - in practice, I have met people with no material possibilities who considered that they should be heard by suit investigators and saw this as a matter of respect; on the other side, there are young people who consider that the official outfit blocks communication as they do not agree to traditional values

${ }^{8}$ N. J. Gordon, W. L. Fleisher, Effective interviewing and interrogation techniques, Elsevier Inc., 2006, p. 42; D. Zulawski, D. Wicklander, Practical Aspects of Interview and Interrogation, CRC Press, Boca Raton LLC, 2002, p. 67.
} 